\title{
Outcome of living-donor lobar lung transplantation using a single donor
}

\author{
Hiroshi Date, MD, ${ }^{\mathrm{a}}$ Takeshi Shiraishi, MD, ${ }^{\mathrm{b}}$ Seiichiro Sugimoto, MD, ${ }^{\mathrm{c}}$ Tsuyoshi Shoji, MD, ${ }^{\mathrm{a}}$ \\ Fengshi Chen, MD, ${ }^{\mathrm{a}}$ Masafumi Hiratsuka, MD, ${ }^{\mathrm{b}}$ Akihiro Aoyama, MD, ${ }^{\mathrm{a}}$ Masaaki Sato, MD, ${ }^{\mathrm{a}}$ \\ Masaomi Yamane, MD, ${ }^{\mathrm{c}}$ Akinori Iwasaki, MD, ${ }^{\mathrm{b}}$ Shinichiro Miyoshi, MD ${ }^{\mathrm{c}}$ Toru Bando, MD, ${ }^{\mathrm{a}}$ and \\ Takahiro Oto, $\mathrm{MD}^{\mathrm{c}}$
}

Objective: Living-donor lobar lung transplantation usually requires 2 healthy donors who donate either a right or a left lower lobe; however, finding 2 healthy donors is difficult. Several case reports have been published on successful living-donor lobar lung transplantation using a single donor; however, little is known about its outcome.

Methods: We retrospectively investigated 14 critically ill patients who had undergone single living-donor lobar lung transplantation at 3 lung transplant centers in Japan. There were 10 female and 4 male patients, including 10 children and 4 adults. Size matching was assessed by estimated graft forced vital capacity and 3-dimensional computed tomography volumetry. The diagnoses included complications of allogeneic hematopoietic stem cell transplantation $(n=6)$, pulmonary hypertension $(n=4)$, and others $(n=4)$.

Results: At a mean follow-up of 45 months (range, 2-128), the 3- and 5-year survival rate was $70 \%$ and $56 \%$, respectively. There were 4 early deaths, for a hospital mortality of $29 \%$, with 1 additional death at 40 months. The main cause of early death was primary graft dysfunction, most likely related to size mismatching. The survival among these 14 patients was significantly worse than the survival in a group of 78 patients undergoing bilateral living-donor lobar lung transplantation during the same period $(P=.044)$.

Conclusions: Single living-donor lobar lung transplantation provides acceptable results for sick patients who would die soon otherwise. However, bilateral living-donor lobar lung transplantation appears to be a better option if 2 living donors are found. (J Thorac Cardiovasc Surg 2012;144:710-5)

Lung transplantation has been performed successfully in a significant number of patients affected by various lung diseases. However, donor organ shortages continue to be problematic with all solid organ transplantation, particularly in lung transplantation. Several strategies to solve this challenging problem have been proposed, including marginal donors, donation after cardiac death, and living donors. Among these strategies, living-donor lobar lung transplantation (LDLLT) has been performed as a lifesaving procedure in approximately 400 patients worldwide. ${ }^{1}$ During the past several years, LDLLT has been almost exclusively performed in Japan, where the average waiting time for cadaveric lungs exceeds 800 days. The results of LDLLT

From the Department of Thoracic Surgery, ${ }^{\text {a }}$ Kyoto University Graduate School of Medicine, Kyoto, Japan; Department of Thoracic Surgery, ${ }^{b}$ Fukuoka University School of Medicine, Fukuoka, Japan; and Department of General Thoracic Surgery, ${ }^{\text {c } O k a y a m a ~ U n i v e r s i t y ~ G r a d u a t e ~ S c h o o l ~ o f ~ M e d i c i n e, ~ D e n t i s t r y, ~ a n d ~ P h a r m a-~}$ ceutical Sciences, Okayama, Japan.

Disclosures: Authors have nothing to disclose with regard to commercial support.

Received for publication Feb 15, 2012; revisions received April 20, 2012; accepted for publication May 16, 2012; available ahead of print June 20, 2012.

Address for reprints: Hiroshi Date, MD, Department of Thoracic Surgery, Kyoto University Graduate School of Medicine, 54 Shogoin-Kawahara-cho, Sakyo-ku, Kyoto 606-8507, Japan (E-mail: hdate@kuhp.kyoto-u.ac.jp).

$0022-5223 / \$ 36.00$

Copyright (c) 2012 by The American Association for Thoracic Surgery doi:10.1016/j.jtcvs.2012.05.054 have been reported to be equal to or better than conventional cadaveric lung transplantation. ${ }^{2-5}$

In LDLLT, the right and left lower lobes from 2 healthy donors are implanted in the recipient in place of whole right and left lungs. However, finding 2 blood-type compatible donors is not easy, especially for children. Several case reports have been published on successful single LDLLT, ${ }^{6-10}$ but little has been reported on the long-term follow-up in these patients. ${ }^{11,12}$ We conducted a 3 -center cooperative retrospective study in Japan to investigate 14 critically ill patients who had undergone single LDLLT.

\section{METHODS}

The present study was a retrospective study of patients who had undergone single LDLLT at 3 transplant centers in Japan. From October 1998 to November 2011, 92 LDLLTs were performed in patients with various lung diseases. Among these, 14 patients received single LDLLT and were the subjects of the present study. The study protocol (E-1022) was approved by the institutional review boards of Kyoto University Hospital, Okayama University Hospital, and Fukuoka University Hospital, where these LDLLTs were performed.

All recipients met the criteria for conventional single lung transplantation and were thought to be too ill to survive the long wait for cadaveric lungs. After the full assessment of the recipients and living donors, each recipient and living donor provided informed consent. Each case was carefully reviewed and approved by the institutional lung transplant evaluation committee. 


\section{Abbreviations and Acronyms \\ 3D-CT $=3$-dimensional computed tomography \\ $\mathrm{FVC}=$ forced vital capacity \\ HSCT $=$ hematopoietic stem cell transplantation \\ LDLLT $=$ living-donor lobar lung transplantation \\ PGD = primary graft dysfunction}

Given that the right lower lobe consists of 5 segments, the left lower lobe 4 , and the whole lung 19, we estimated the graft forced vital capacity (FVC) using the following equation:

$$
\begin{aligned}
\text { Right graft FVC } & =\text { measured FVC of the right donor } \times 5 / 19 \\
\text { Left graft FVC } & =\text { measured FVC of the left donor } \times 4 / 19
\end{aligned}
$$

A size disparity was acceptable only when the FVC of the donor lobe was $45 \%$ or more of the predicted FVC of the recipient (calculated according to height, age, and gender). ${ }^{5}$

Three-dimensional computed tomography (3D-CT) volumetry was performed for both the donor and the recipient in 11 recent single LDLLTs. The CT images were obtained using a multidetector CT scanner during a single respiratory pause at the end of maximum inspiratory effort.

The surgical aspects of donor lobectomy and graft implantation under the condition of cardiopulmonary bypass have been previously described in detail. ${ }^{6-10}$ Postoperative immunosuppression consisted of triple-drug therapy with cyclosporine or tacrolimus, azathioprine or mycophenolate mofetil, and corticosteroids without the use of induction cytolytic therapy. Acute rejection was judged on the basis of radiographic and clinical findings without transbronchial lung biopsy to avoid intragraft bleeding. Acute rejection was treated with a daily bolus dose of $10 \mathrm{mg} / \mathrm{kg}$ methylprednisolone for 3 days.

For all 14 patients and 14 living donors, the inpatient and outpatient medical records were retrospectively reviewed. The survival of the 14 patients undergoing single LDLLT was compared with that of 78 patients who underwent bilateral LDLLT during the same period. The survival times were calculated from the date of LDLLT. The results were analyzed as of January 10, 2012.

\section{Statistical Analysis}

The data are presented as the mean \pm standard error of the mean. The size matching data were evaluated using Student's $t$ test for 2-group analysis. Observed survival data are reported as Kaplan-Meier estimates; the log-rank test was used to explore the significance of the difference between the 2 groups.

\section{RESULTS \\ Recipient Characteristics}

The clinical characteristics of the 14 patients undergoing single LDLLT are listed in Table 1 . The age range of the 10 female and 4 male patients was 4 to 48 years (average, 17.8). Of the 14 patients, 10 were children and 4 were adults.

Six patients developed bronchiolitis obliterans and/or pulmonary fibrosis as complications of allogeneic hematopoietic stem cell transplantation (HSCT). We confirmed that all the patients converted to full donor chimerism. Of these 6 patients, 3 (patients 3, 4, and 9) received a lobe from the same living-donor as for HSCT. The diagnoses for HSCT included myelodysplastic syndrome (patients 2 and 7), acute myelomonocytic leukemia (patient 3 ), acute lymphatic leukemia (patient 4), primary macroglobulinemia (patient 9), and severe combined immunodeficiency (patient 12). The mean interval between HSCT and single LDLLT was 54.8 months (range, 9-129 months). One patient (patient 2) had an interval of less than 2 years, but the relapse rate of the original hematopoietic disorder was estimated to be less than $20 \%$ by expert hematologists.

Four patients were diagnosed with pulmonary hypertension, resulting from pulmonary veno-occlusive disease $(\mathrm{n}=2)$, idiopathic pulmonary arterial hypertension $(\mathrm{n}=1)$, and repaired transposition of the great arteries $(\mathrm{n}=1)$. Other diagnoses were lymphangioleiomyomatosis $(\mathrm{n}=1)$, bronchiolitis obliterans after Steven-Johnson syndrome $(\mathrm{n}=1)$, idiopathic pulmonary fibrosis $(\mathrm{n}=1)$, and pulmonary fibrosis caused by chemotherapy for breast cancer $(\mathrm{n}=1)$.

All patients were hospital bound and were dependent on continuous oxygen inhalation. Of the 14 patients, 4 (patients 3, 6, 7 and 13) required a ventilator at single LDLLT.

\section{Donor Characteristics}

Among the 14 living donors, 9 were the mothers of the recipients, 3 were husbands, 1 was a father, and 1 was a sister, with an age range of 28 to 49 years (average, 38.0 years).

\section{Surgical Procedure}

Of the 14 patients, 7 patients underwent single LDLLT at Kyoto University, 4 at Okayama University, and 3 at $\mathrm{Fu}-$ kuoka University.

Thirteen of 14 patients received a right single LDLLT and 1 (patient 3) received a left single LDLLT. Three patients (patients 2, 7, and 12) undergoing right single LDLLT required simultaneous left pneumonectomy to provide more space for the oversized graft, with the expectation that the mediastinum would shift toward the left. In 3 additional patients (patients 10,13, and 14), the chest was temporarily closed without rib approximation owing to the oversized graft. Delayed chest closure was performed on day 1 in 2 patients and day 17 in 1 patient.

One patient (patient 12) with a funnel chest had an extremely small chest cavity and required graft downsizing by removal of the superior segment of the oversized right lower lobe graft. The removed segment was then implanted as a left graft after left pneumonectomy. The left graft became congestive, and graftectomy was performed on day 1 . We did not downsize the donor lobe in any other patient.

One patient (patient 14) undergoing right single LDLLT required a left single LDLLT on day 17 because of progressive graft dysfunction. Massive airway bleeding without a detectable cause occurred immediately after reperfusion. 
TABLE 1. Clinical patient characteristics

\begin{tabular}{|c|c|c|c|c|c|}
\hline Pt. no. & $\begin{array}{l}\text { Age, } \\
\text { gender }\end{array}$ & Diagnosis & $\begin{array}{l}\text { Preoperative } \\
\text { condition }\end{array}$ & $\begin{array}{l}\text { Donor age, gender, } \\
\text { relation } \\
\end{array}$ & Transplant procedure \\
\hline $1^{7,11}$ & $10 \mathrm{y}, \mathrm{M}$ & IPAH & WHO 3 & $38 \mathrm{y}, \mathrm{F}$, mother & $\mathrm{R}$ single-lobe $\mathrm{Tx}$ \\
\hline $2^{23}$ & $6 \mathrm{y}, \mathrm{F}$ & $\mathrm{BO} / \mathrm{PF}$ after $\mathrm{HSCT}$ & H-J 5 & $35 \mathrm{y}, \mathrm{F}$, mother & $\mathrm{R}$ single-lobe Tx, left pneumonectomy \\
\hline $3^{10,12,23}$ & $4 \mathrm{y}, \mathrm{M}$ & BO after HSCT & Ventilator for $4 \mathrm{wk}$ & $28 \mathrm{y}, \mathrm{F}$, mother & L single-lobe $\mathrm{Tx}$ \\
\hline $4^{23}$ & $13 \mathrm{y}, \mathrm{M}$ & BO after HSCT & H-J 5 & $34 \mathrm{y}, \mathrm{F}$, mother & $\mathrm{R}$ single-lobe $\mathrm{Tx}$ \\
\hline 5 & $30 \mathrm{y}, \mathrm{F}$ & LAM & H-J 4 & $30 \mathrm{y}, \mathrm{M}$, husband & $\mathrm{R}$ single-lobe $\mathrm{Tx}$ \\
\hline $6^{8}$ & $6 \mathrm{y}, \mathrm{F}$ & BO after SJS & Ventilator for $7 \mathrm{mo}$ & $35 \mathrm{y}, \mathrm{F}$, mother & $\mathrm{R}$ single-lobe $\mathrm{Tx}$ \\
\hline $7^{9,23}$ & $8 \mathrm{y}, \mathrm{F}$ & $\mathrm{BO} / \mathrm{PF}$ after $\mathrm{HSCT}$ & Ventilator for $11 \mathrm{wk}$ & $33 \mathrm{y}, \mathrm{F}$, mother & $\mathrm{R}$ single-lobe $\mathrm{Tx}$, left pneumonectomy \\
\hline 8 & $43 \mathrm{y}, \mathrm{F}$ & PVOD & WHO 4 & $44 \mathrm{y}, \mathrm{M}$, husband & $\mathrm{R}$ single-lobe $\mathrm{Tx}$ \\
\hline $9^{23}$ & $41 \mathrm{y}, \mathrm{F}$ & BO after HSCT & H-J 5 & $39 \mathrm{y}, \mathrm{F}$, sister & $\mathrm{R}$ single-lobe $\mathrm{Tx}$ \\
\hline 10 & $6 \mathrm{y}, \mathrm{F}$ & IPF & H-J 5 & $44 \mathrm{y}, \mathrm{F}$, mother & $\mathrm{R}$ single-lobe $\mathrm{Tx}$, delayed chest closure (1 POD) \\
\hline 11 & $48 \mathrm{y}, \mathrm{F}$ & PF after chemotherapy & H-J 5 & $49 \mathrm{y}, \mathrm{M}$, husband & $\mathrm{R}$ single-lobe $\mathrm{Tx}$ \\
\hline 12 & $11 \mathrm{y}, \mathrm{M}$ & $\begin{array}{l}\mathrm{BO} / \mathrm{PF} \text { after } \mathrm{HSCT} \\
\text { funnel chest }\end{array}$ & H-J 5 & $46 \mathrm{y}, \mathrm{F}$, mother & $\begin{array}{l}\mathrm{R} \text { single-lobe Tx, graft } \mathrm{S} 6 \text { segmentectomy, left } \\
\text { pneumonectomy }\end{array}$ \\
\hline 13 & $6 \mathrm{y}, \mathrm{F}$ & PVOD & Ventilator for $5 \mathrm{~d}$ & $38 \mathrm{y}, \mathrm{F}$, mother & $\mathrm{R}$ single-lobe Tx, delayed chest closure (1 POD) \\
\hline 14 & $12 \mathrm{y}, \mathrm{F}$ & Repaired TGA + PH & WHO 4 & $39 \mathrm{y}, \mathrm{M}$, father & $\begin{array}{l}\mathrm{R} \text { single-lobe Tx, delayed chest closure (13 POD), } \\
\mathrm{L} \text { single-lobe Tx (17 POD) }\end{array}$ \\
\hline
\end{tabular}

Pt. no., Patient number; $M$, male; $I P A H$, idiopathic pulmonary arterial hypertension; $W H O$, World Health Organization; $F$, female; $R$, right; $T x$, transplantation; $B O$, bronchiolitis obliterans; $P F$, pulmonary fibrosis; $H S C T$, hematopoietic stem cell transplantation; $H-J$, Hugh-Jones; $L$, left; $L A M$, lymphangioleiomyomatosis; SJS, Steven-Johnson syndrome; $P V O D$, pulmonary veno-occlusive disease; $I P F$, idiopathic pulmonary fibrosis; $P O D$, postoperative day; $T G A$, transposition of the great arteries; $P H$, pulmonary hypertension.

Left graft function was lost, and left graftectomy was required.

\section{Size Matching and Primary Graft Dysfunction}

The size matching data are listed in Table 2. The recipient height ranged from 98 to $163 \mathrm{~cm}$ (average, $124.5 \mathrm{~cm}$ ), and the weight ranged from 12.4 to $58 \mathrm{~kg}$ (average, $24.7 \mathrm{~kg}$ ). The donor height ranged from 153 to $182 \mathrm{~cm}$ (average, $164.4 \mathrm{~cm}$ ), and the weight ranged from 45.1 to $90.5 \mathrm{~kg}$ (average, $60.4 \mathrm{~kg}$ ).

The estimated graft FVC (according to the donor's measured FVC and the number of segments implanted ) was
$1009 \pm 80 \mathrm{~mL}$ (range, 503-1587 mL). Compared with the recipient predicted $\mathrm{FVC}$, the graft $\mathrm{FVC}$ was $63.1 \% \pm$ $4.0 \%$ (range, $47.3-90.5 \%$ ).

The graft volume measured using 3D-CT volumetry was $1300 \pm 110 \mathrm{~mL}$ (range, 676-1906 mL). The recipient hemithorax volume was $914 \pm 175 \mathrm{~mL}$ (range, 338-2148 mL). The graft volume/recipient hemithorax volume ratio was $175 \% \pm 27 \%$ (range, $80.5-395 \%$ ).

Severe primary graft dysfunction (PGD) requiring extracorporeal membrane oxygenation occurred in 4 patients (patients 8,11,12, and 14). Size matching data were compared between the non-PGD and PGD patients.

TABLE 2. Size matching and outcome of 14 patients undergoing single living-donor lobar lung transplantation

\begin{tabular}{|c|c|c|c|c|c|c|c|c|c|}
\hline $\begin{array}{l}\text { Pt. } \\
\text { no. }\end{array}$ & $\begin{array}{c}\text { Age, } \\
\text { gender }\end{array}$ & $\begin{array}{c}\text { Recipient } \\
\text { height }(\mathrm{cm}), \\
\text { weight }(\mathrm{kg}) \\
\end{array}$ & $\begin{array}{c}\text { Donor } \\
\text { height }(\mathbf{c m}), \\
\text { weight }(\mathbf{k g}) \\
\end{array}$ & $\begin{array}{l}\text { Size matching } \\
\text { graft FVC (\%) }\end{array}$ & $\begin{array}{c}\text { Size matching CT } \\
\text { volumetry }(\%) \\
\end{array}$ & $\begin{array}{r}\text { PGD grade } \\
\text { and ECMO } \\
\end{array}$ & $\begin{array}{c}\text { Outcome after } \\
\text { transplant }\end{array}$ & $\begin{array}{l}\text { Current } \\
\text { condition } \\
\end{array}$ & $\begin{array}{c}\text { Cause of } \\
\text { death }\end{array}$ \\
\hline 1 & $10 \mathrm{y}, \mathrm{M}$ & $122.7,20.4$ & 158,52 & 52.3 & NA & 0 & $10 \mathrm{y}, 8 \mathrm{mo}$, alive & H-J 2 & \\
\hline 2 & $6 \mathrm{y}, \mathrm{F}$ & $106,18.5$ & $160,48.5$ & 79.4 & NA & 0 & $61 \mathrm{~d}$, died & & Aspergillosis \\
\hline 3 & $4 \mathrm{y}, \mathrm{M}$ & 98,13 & $159.5,55$ & 78.0 & 118 & 0 & $5 \mathrm{y}, 2 \mathrm{mo}$, alive & H-J 1 & \\
\hline 4 & $13 \mathrm{y}, \mathrm{M}$ & 125,16 & $167,51.5$ & 47.3 & 119 & 0 & $3 \mathrm{y}, 4 \mathrm{mo}$, died & & Unknown \\
\hline 5 & $30 \mathrm{y}, \mathrm{F}$ & $153.3,47$ & $178.0,76$ & 53.0 & NA & 0 & $4 \mathrm{y}, 5 \mathrm{mo}$, alive & H-J 1 & \\
\hline 6 & $6 \mathrm{y}, \mathrm{F}$ & $113,15.4$ & 160,58 & 73.3 & 161 & 0 & $3 \mathrm{y}, 7 \mathrm{mo}$, alive & H-J 2 & \\
\hline 7 & $8 \mathrm{y}, \mathrm{F}$ & $111,12.4$ & 162,68 & 67.0 & 200 & 0 & $3 \mathrm{y}, 3 \mathrm{mo}$, alive & H-J 2 & \\
\hline 8 & $43 \mathrm{y}, \mathrm{F}$ & 163,58 & $182,95.9$ & 55.8 & 88.7 & 3, ECMO & $103 \mathrm{~d}$, died & & PGD, sepsis \\
\hline 9 & $41 \mathrm{y}, \mathrm{F}$ & $128,32.1$ & $164.5,58.2$ & 45.1 & 80.5 & 0 & $3 \mathrm{y}, 2 \mathrm{mo}$, alive & H-J 2 & \\
\hline 10 & $6 \mathrm{y}, \mathrm{F}$ & $105,13.4$ & 163,55 & 90.5 & 207 & 0 & $1 \mathrm{y}, 6 \mathrm{mo}$, alive & H-J 1 & \\
\hline 11 & $48 \mathrm{y}, \mathrm{F}$ & 156,37 & 171,70 & 54.4 & 207 & 3, ECMO & $10 \mathrm{~d}$, died & & PGD \\
\hline 12 & $11 \mathrm{y}, \mathrm{M}$ & $125.2,16.9$ & $164,53.3$ & 50.7 & 395 & 3, ECMO & $14 \mathrm{~d}$, died & & PGD \\
\hline 13 & $6 \mathrm{y}, \mathrm{F}$ & 109,16 & 153,40 & 78.9 & 173 & 0 & $6 \mathrm{mo}$, alive & H-J 1 & \\
\hline 14 & $12 \mathrm{y}, \mathrm{F}$ & $127.7,29$ & 160,64 & 57.0 & 179 & 3, ECMO & 2 mo, alive & in ICU & \\
\hline
\end{tabular}

Pt. no., Patient number; $F V C$, forced vital capacity; $C T$, computed tomography; $P G D$, primary graft dysfunction; $E C M O$, extracorporeal membrane oxygenation; $M$, male; $N A$, not assessed; $H-J$, Hugh-Jones; $F$, female; $I C U$, intensive care unit. 
FVC size matching

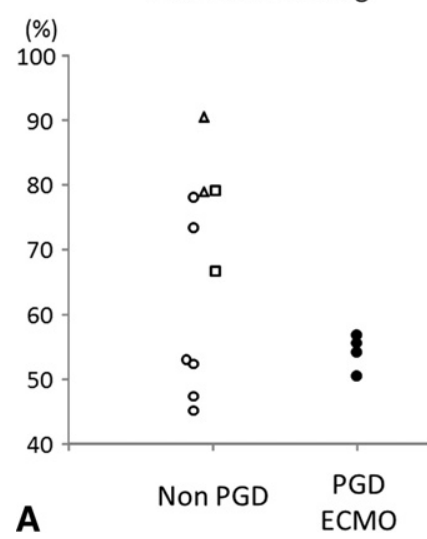

3D-CT size matching

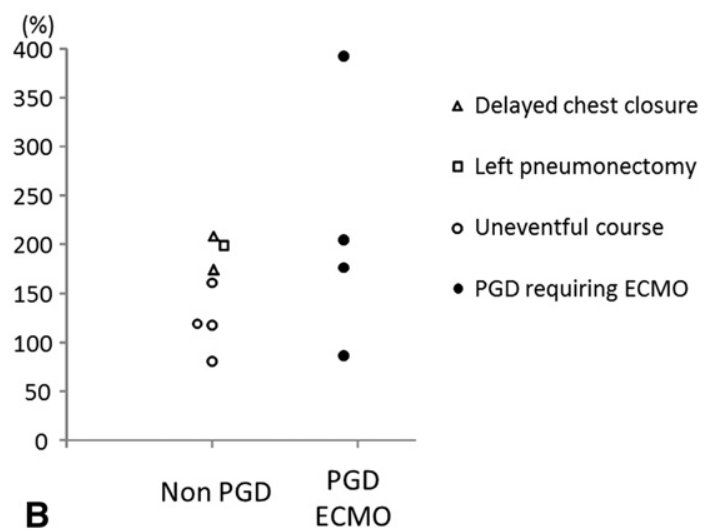

FIGURE 1. A, Forced vital capacity $(F V C)$ size matching. Graft FVC was $66.5 \% \pm 5.0 \%$ in non-primary graft dysfunction $(P G D)$ patients and $54.5 \% \pm$ $1.4 \%$ in PGD patients $(P=.169)$. Note, all 4 PGD patients had graft FVC of $60 \%$ or less. B, Three-dimensional computed tomography $(3 D-C T)$ size matching. The graft volume/recipient hemithorax volume ratio measured using 3D-CT volumetry was $151.2 \% \pm 17.7 \%$ in non-PGD patients and $217.4 \% \pm$ $64.4 \%$ in PGD patients $(P=.238)$. Note, all 6 patients who had a volume ratio of $\geq 170 \%$ required additional procedures, such as extracorporeal membrane oxygenation $(E C M O)$ support for severe PGD, delayed chest closure, or left pneumonectomy.

The graft FVC was $66.5 \% \pm 5.0 \%$ in the non-PGD patients and $54.5 \% \pm 1.4 \%$ in the PGD patients $(P=.169$; Figure 1, A). All 4 PGD patients had a graft FVC of $60 \%$ or less.

The graft volume/recipient hemithorax volume ratio, as measured using 3D-CT volumetry, was $151.2 \% \pm 17.7 \%$ in the non-PGD patients and $217.4 \% \pm 64.4 \%$ in the PGD patients $(P=.238$; Figure $1, B)$. All 6 patients with a ratio of $170 \%$ or greater required additional procedures such as extracorporeal membrane oxygenation support for severe PGD $(n=3)$, delayed chest closure $(n=2)$, or left pneumonectomy $(\mathrm{n}=1)$.

Figure 2 illustrates the association between the FVC size matching and the 3D-CT size matching. All 3 patients who had graft FVC of $60 \%$ or less and 3D-CT volume of $170 \%$ or greater developed severe PGD.

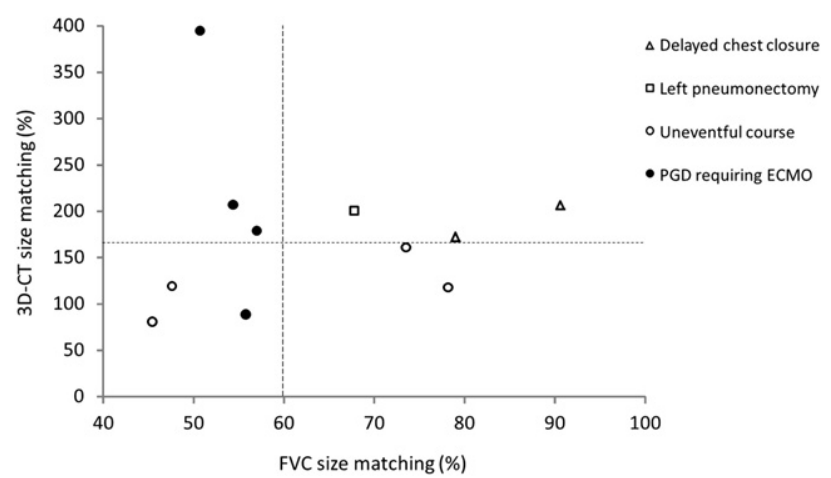

FIGURE 2. The association between forced vital capacity $(F V C)$ size matching and 3-dimensional computed tomography (3D-CT) size matching. Note, all 3 patients who had graft FVC of $60 \%$ or less and a 3D-CT volume ratio of $170 \%$ or more developed severe primary graft dysfunction $(P G D)$ requiring extracorporeal membrane oxygenation $(E C M O)$ support.

\section{Recipient Outcome}

There were 4 early deaths, for a hospital mortality of $29 \%$. Three patients (patients 8, 11, and 12) died of PGD 10 to 103 days after transplantation. One patient (patient 2) died of aspergillosis (Aspergillus tereus) on day 61, although the early postoperative course had been uneventful. One additional patient (patient 4) died at 40 months; the patient was found dead in the morning of an unknown cause.

At the final data analysis on January 10, 2012, the mean interval from single LDLLT to the final analysis for the 14 patients was 45 months (range, 2-128 months). The 1,3, and 5 year survival for the 14 recipients was $70 \%, 70 \%$, and $56 \%$, respectively. The survival among the 14 patients undergoing single LDLLT was significantly worse than that of a group of 78 patients who underwent bilateral LDLLT during the same period $(P=.044$; Figure 3$)$.

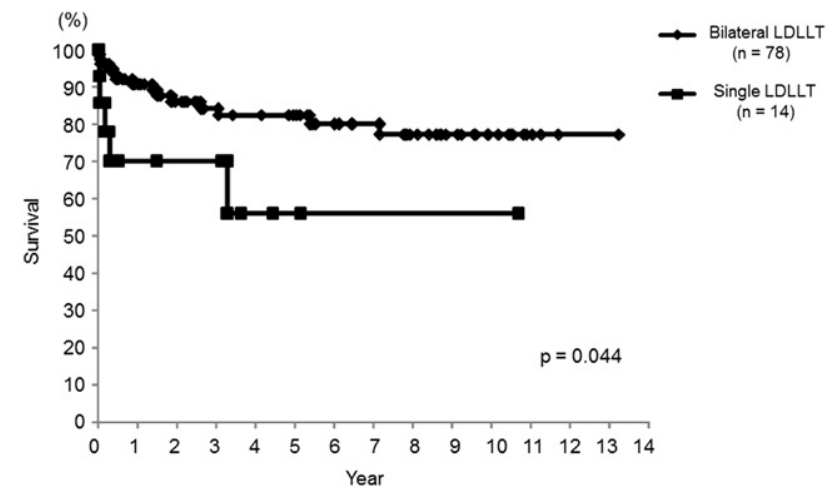

FIGURE 3. Actuarial survival after single living-donor lobar lung transplantation $(L D L L T)(\mathrm{n}=14)$ compared with that after bilateral LDLLT $(\mathrm{n}=78)$. Bilateral LDLLT provided significantly better survival than single $\operatorname{LDLLT}(P=.044)$. 
Of the 9 currently surviving recipients, bronchiolitis obliterans syndrome occurred in 2 patients at 84 (patient 1) and 24 (patient 6) months. By increasing immunosuppression, the forced expiratory volume in 1 second for these 2 patients reached a plateau within 6 months. Except for 1 patient who had recently undergone single LDLLT, all 8 survivors were able to perform daily activities without oxygen inhalation with a Hugh-Jones I $(\mathrm{n}=4)$ or II $(\mathrm{n}=4)$ classification. The percentage of FVC was $61.3 \%$ $\pm 4.2 \%$, and the 6-minute walking distance was $407 \pm$ $25 \mathrm{~m}$ at 6 to 12 months.

\section{Donor Outcome}

No significant operative morbidity occurred with donor lobectomy, except that 1 donor developed mild temporary hemosputum. All 14 donors returned to their previous lifestyles during the observation period.

\section{DISCUSSION}

LDLLT was introduced by Starnes and colleagues ${ }^{13}$ as an alternative form of treatment for patients with a decline in physical condition with a limited life expectancy. The first patient was an 11-year-old girl with bronchopulmonary dysplasia. In 1990, she underwent right single LDLLT using the right upper lobe of her mother and survived. The second patient was a 3-year-girl with Eisenmenger syndrome. She underwent right single LDLLT using the middle lobe of her father plus ventricular septal defect closure; however, she died of PGD that developed immediately after reperfusion. After the unsuccessful result in the second case, they developed bilateral LDLLT in which 2 healthy donors donated their right or left lower lobes. ${ }^{14,15}$ Since then, bilateral LDLLT has been performed worldwide as a lifesaving procedure. The results of bilateral LDLLT have been equal to or better than conventional cadaveric lung transplantation. ${ }^{2-5}$

We accept only immediate family members (relatives within the third degree or a spouse) as living donors, and their ABO blood type must be compatible with that of the recipient. With these donor selection criteria, finding 2 suitable living donors is not easy. We, and others, have reported anecdotal successful single LDLLT $^{6-12}$; however, the results of a single LDLLT series have never been reported. Because each transplant center has a quite limited number of single LDLLT cases, a 3-center cooperative study was conducted. We believe that the present study cohort of 14 patients undergoing single LDLLT represents more than $70 \%$ of the worldwide experience with this rare procedure.

Because only 1 lobe is implanted in single LDLLT, appropriate size matching between the donor and recipient is extremely important. When the lobe is too small for the recipient, pulmonary edema will develop in the transplanted single lobe because a preponderance of pulmonary flow will be directed to the transplanted lobe as a result of greater pulmonary vascular resistance in the remaining diseased native lung. ${ }^{16}$ When the lobe is too large for the hemithorax of the recipient, it will cause high airway resistance, atelectasis, and hemodynamic instability at chest closure. ${ }^{17}$

For "functional size matching," we used the percentage of graft FVC. It has been used to determine the lowest threshold $(45 \%)$ ) for undersized grafts. ${ }^{5,18}$ For "anatomic size matching", 3D-CT volumetry has recently been introduced. ${ }^{19,20}$ It was reported to be useful in evaluating oversized grafts ${ }^{21}$; however, an upper threshold has not yet been determined.

Four patients (29\%) developed severe PGD, resulting in extracorporeal membrane oxygenation support, and PGD was found to be the major cause of early mortality after single LDLLT. However, the remaining 10 patients (71\%), including 2 patients who underwent simultaneous left pneumonectomy, were weaned off bypass without developing PGD. ${ }^{10}$

As shown in Figure 1, $A$, all 4 PGD patients had a graft FVC of $60 \%$ or less. However, it should also be noted that 4 other patients with a graft FVC of $60 \%$ or less had an uneventful postoperative course. Figure 1, B, shows that 3 of 4 PGD patients had a graft 3D-CT volume of $170 \%$ or more. Although 3 non-PGD patients also had a 3D-CT volume ratio of $170 \%$ or more, they all required additional procedures, such as left pneumonectomy or delayed chest closure. We found combining "functional size matching" and "anatomic size matching" to be of great importance for single LDLLT (Figure 2). All 3 patients who had a graft FVC of $60 \%$ or less and a 3D-CT volume ratio of $170 \%$ or greater developed severe PGD, suggesting that a lobe that is "small for the body but large for the chest cavity" should not be implanted.

Although the hospital mortality rate was relatively high, the intermediate-term survival after single LDLLT was encouraging. The overall actuarial survival of $70 \%, 70 \%$, and $56 \%$ at 1,3 , and 5 years, respectively, was comparable to that for reported cadaveric lung transplantation from the International Society for Heart and Lung Transplantation Registry $\left(79 \%, 64 \%\right.$, and $53 \%$, respectively). ${ }^{22}$ Bronchiolitis obliterans syndrome has been the major obstacle after cadaveric lung transplantation. However, bronchiolitis obliterans syndrome was seen in only 2 recipients and was not a cause of death in the present study cohort. Three patients who received a lobe from the same donor as for previous HSCT required no or minimal immunosuppression without developing rejection. ${ }^{23}$ With only 1 lobe transplanted, the survivors have been able to perform daily activities and to attend school. Knowing that the preoperative condition of our patients was very poor, with $100 \%$ hospital bound and $29 \%$ ventilator dependent, single LDLLT provided acceptable intermediate results for very ill patients whose life expectancy was quite limited.

A number of studies have reported that bilateral lung transplantation provides better long-term survival than 
single lung transplantation. ${ }^{22,24,25}$ Likewise, the survival of $90 \%, 84 \%$, and $82 \%$ at 1,3 , and 5 years, respectively, after bilateral LDLLT was better than that after single LDLLT. When 2 suitable living donors are found, bilateral LDLLT is certainly a better option.

\section{CONCLUSIONS}

The present 3-center cooperative study showed that single LDLLT provides acceptable intermediate results for sick patients when only 1 suitable living donor is available. Size matching is very important, and graft FVC and 3D-CT volumetry provide useful information for this. A lobe that is small for the body but large for the chest cavity should not be used. Bilateral LDLLT is a better option if 2 living donors can be found.

\section{References}

1. Date H. Update on living-donor lobar lung transplantation. Curr Opin Organ Transplant. 2011;16:453-7.

2. Starnes VA, Bowdish ME, Woo MS, Barbers RG, Schenkel FA, Horn MV, et al. A decade of living lobar lung transplantation: recipient outcomes. J Thorac Cardiovasc Surg. 2004;127:114-22.

3. Sweet SC. Pediatric living donor lobar lung transplantation. Pediatr Transplant. 2006; $10: 861-8$

4. Date H, Aoe M, Sano Y, Nagahiro I, Miyaji K, Goto K, et al. Improved survival after living-donor lobar lung transplantation. J Thorac Cardiovasc Surg. 2004; 28:933-40.

5. Date H, Yamane M, Toyooka S, Okazaki M, Aoe M, Sano Y. Current status and potential of living-donor lobar lung transplantation. Front Biosci. 2008;13: 1433-9.

6. Svendsen UG, Aggestrup S, Heimann C, Jacobsen N, Koch C, Larsen B, et al. Transplantation of a lobe of lung from mother to child following previous transplantation with maternal bone marrow. Eur Respir J. 1995;8:334-7.

7. Date H, Sano Y, Aoe M, Matsubara H, Kusano K, Goto K, et al. Living-donor single lobe lung transplantation for primary pulmonary hypertension in a child. $J$ Thorac Cardiovasc Surg. 2002;123:1211-3

8. Shoji T, Bando T, Fujinaga T, Date H. Living-donor single-lobe lung transplant in a 6-year-old girl after 7-month mechanical ventilator support. J Thorac Cardiovasc Surg. 2010;139:e112-3.

9. Sonobe M, Bando T, Kusuki S, Fujinaga T, Shoji T, Chen F, et al. Living-donor, single-lobe lung transplantation and simultaneous contralateral pneumonectomy in a child. J Heart Lung Transplant. 2011;30:471-4.

10. Shiraishi T, Hiratsuka M, Munakata M, Higuchi T, Makihata S, Yoshinaga Y, et al. Living-donor single-lobe lung transplantation for bronchiolitis obliterans in a 4-year-old boy. J Thorac Cardiovasc Surg. 2007;134:1092-3.
11. Toyooka S, Sano Y, Yamane M, Oto T, Okazaki M, Kusano K, et al. Long-term follow-op of living-donor single lobe transplantation for idiopathic pulmonary arterial hypertension in a child. J Thorac Cardiovasc Surg. 2008;135:451-2.

12. Hiratsuka M, Shiraishi T, Higuchi T, Iwasaki A. Long-term follow-up of livingdonor single-lobe lung transplantation for bronchiolitis obliterans in a four-yearold male: improvement of over-sized lung allograft. Interact Cardiovasc Thorac Surg. 2011;41:490-5.

13. Starnes VA, Lewiston NJ, Luikart H, Theodore J, Stinson EB, Shumway NE. Current trends in lung transplantation. Lobar transplantation and expanded use of single lungs. J Thorac Cardiovasc Surg. 1992;104:1060-6.

14. Starnes VA, Barr ML, Cohen RG. Lobar transplantation: indication, technique, and outcome. J Thorac Cardiovasc Surg. 1994;108:403-11.

15. Cohen RG, Barr ML, Schenkel FA, DeMeester TR, Wells WJ, Starnes VA. Living-related donor lobectomy for bilateral lobar transplantation in patients with cystic fibrosis. Ann Thorac Surg. 1994;57:1423-8.

16. Fujita T, Date H, Ueda K, Nagahiro I, Aoe M, Andou A, et al. Experimental study on size matching in a canine living-donor lobar lung transplant model. $J$ Thorac Cardiovasc Surg. 2002;123:104-9.

17. Oto T, Date H, Ueda K, Hayama M, Nagahiro I, Aoe M, et al. Experimental study of oversized grafts in a canine living-donor lobar lung transplantation model. $J$ Heart Lung Transplant. 2001;20:1325-30.

18. Date H, Aoe M, Nagahiro I, Sano Y, Matsubara H, Goto K, et al. How to predict forced vital capacity after living-donor lobar-lung transplantation. J Heart Lung Transplant. 2004;23:547-51.

19. Camargo JJP, Irion KL, Marchiori E, Hochhegger B, Porto NS, Moraes BG, et al Computed tomography measurement of lung volume in preoperative assessmen for living donor lung transplantation: volume calculation using 3D surface rendering in the determination of size compatibility. Pediatr Transplant. 2009;13: 429-39.

20. Kojima K, Kato K, Oto T, Mitsuhashi T, Shinya T, Sei T, et al. Preoperative graf volume assessment with 3D-CT volumetry in living-donor lobar lung transplantations. Acta Med Okayama. 2011;65:265-8.

21. Chen F, Fujinaga T, Shoji T, Yamada T, Nakajima D, Sakamoto J, et al. Perioperative assessment of oversized lobar graft downsizing in living-donor lobar lung transplantation using three-dimensional computed tomographic volumetry. Transpl Int. 2010;23:e41-4.

22. Christie JD, Edwards LB, Kucheryavaya AY, Benden C, Dobbels F, Kirk R, et al The registry of the International Society for Heart and Lung Transplantation: twenty-eighth adult lung and heart-lung transplant report-2011. J Heart Lung Transplant. 2011;30:1104-22.

23. Chen F, Yamane M, Inoue M, Shiraishi T, Oto T, Minami M, et al. Less maintenance immunosuppression in lung transplantation following hematopoietic stem cell transplantation from the same living donor. Am J Transplant. 2011;11: 1509-16.

24. Mendeloff EN, Meyers BF, Sundt TM, Guthrie TJ, Sweet SC, de la Morena M et al. Lung transplantation for pulmonary vascular disease. Ann Thorac Surg. 2002;73:209-17.

25. Thabut G, Christie JD, Ravaud P, Castier Y, Brugière O, Fournier M, et al. Survival after bilateral versus single lung transplantation for patients with chronic obstructive pulmonary disease: a retrospective analysis of registry data. Lancet. 2008;371:744-51. 